\title{
The Frequency and Management of TP53 Mutation Carriers in Turkish Patients with BRCA-Negative Breast Cancer Under 50 Years of Age
}

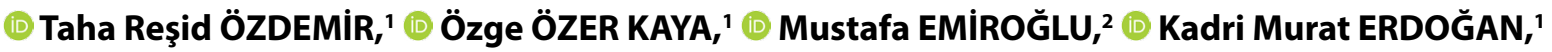

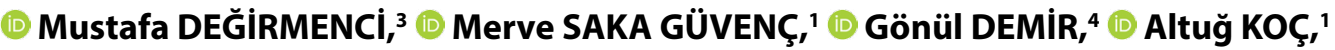 \\ (1) Berk ÖZYILMAZ,' 1 ÖZgür KIRBIYIK'
}

${ }^{1}$ Health Sciences University İzmir Tepecik Training and Research Hospital, Genetic Diagnostic Center, İzmir-Turkey 2Department of General Surgery, Health Sciences University İzmir Tepecik Training and Research Hospital, İzmir-Turkey ${ }^{3}$ Department of Medical Oncology, Health Sciences University İzmir Tepecik Training and Research Hospital, İzmir-Turkey ${ }^{4}$ Department of Radiation Oncology, Health Sciences University İzmir Tepecik Training and Research Hospital, İzmir-Turkey

\section{OBJECTIVE}

Germline mutations in the TP53 gene cause Li-Fraumeni Syndrome (LFS). Breast cancer (BC) is the most common cancer that is seen in young women with LFS. The majority of BC in LFS occurs between 15 and 44 age of years. The present study aims to determine the frequency of TP53 gene germline mutation carriers in Turkish patients with BRCA-negative BC under 50 years of age as the first study from Turkey, to our knowledge, and to emphasize the importance of management in TP53 gene mutation carriers.
\end{abstract}

\section{METHODS}

One hundred patients with BRCA-negative BC younger than 50 years old were evaluated concerning mutations in the TP53 gene between 2016 and 2017 years. Sequencing analysis using targeted next-generation sequencing (NGS) and deletion/duplication analysis using multiplex ligation-dependent probe amplification (MLPA) method were performed in TP53 gene in all patients.

\section{RESULTS}

Five variants were identified in five of 100 patients (5\%) in this study. Four of them were evaluated as known as pathogenic/likely pathogenic $(4 \% ; 4 / 100)$. One variant was evaluated as a variant of uncertain clinical significance (VUS).

\section{CONCLUSION}

The patients with BRCA-negative BC younger than 50 years old should be evaluated concerning TP53 gene mutations because of increased lifetime risk of various developing cancer. Appropriate genetic counseling should be given to patients with TP53 gene mutations, and the follow-up of these patients should be provided multidisciplinary.

Keywords: BRCA-negative breast cancer; early-onset; Li-Fraumeni syndrome; molecular analysis; TP53 gene. Copyright $\odot$ 2020, Turkish Society for Radiation Oncology 


\section{Introduction}

Approximately $5-10 \%$ of all breast cancer (BC) in women is hereditary BC. Hereditary breast-ovarian cancer (HBOC) syndrome and Li-Fraumeni syndrome (LFS) are the most common cause of inherited BC. HBOC arises from germline mutations in BRCA1 and BRCA2 genes that are responsible for approximately half of all cases with hereditary BC. TP53, PTEN and CDH1 genes are the other highpenetrance genes that play an important role in the genetic etiology of BC.[1]

TP53 gene is a tumor suppressor gene (also known as the guardian of the genome). The TP53 protein plays a major role in response to cell damage. Mutations in the TP53 gene lead to LFS that has a predisposition to a wide range of cancers, including BC and childhood cancers (sarcomas, leukemia, brain tumor, adrenocortical carcinoma). Women with LSF are at high risk for developing BC (up to $85 \%$ by age 60 years).[2] However, radiotherapy in $\mathrm{BC}$ patients with a mutation in TP53 gene could be a risk factor for developing a second primary cancer.[3]

The most common feature of inherited BC is an early-onset. Several studies conducted on a mutation screening in the TP53 gene in patients with BRCA negative $\mathrm{BC}$, but there are differences in the threshold for age. $[2,4,5]$ However, patients with LFS have a 25-fold increased risk of developing cancer under 50 years of age compared with the general population. For these reasons, we evaluated 100 patients with BRCA negative $\mathrm{BC}$ under 50 years of age concerning mutation in the TP53 gene.

In this study, we emphasize the importance of diagnosing LFS in patients with BRCA negative BC under 50 years of age for patient management, a mutation screening of asymptomatic kindred and for giving accurate and reliable genetic counseling.

\section{Materials and Methods}

\section{Patients}

The files of patients with BC who were tested for a mutation in BRCA genes between 2016 and 2017 years were reviewed in the Genetic Diagnostic Center. One hundred patients with BRCA negative BC diagnosed at age 50 years or younger were selected regardless of family history. All patients underwent genetic counseling. It was decided to perform molecular tests in the TP53 gene.
Ethics committee approval was received for this study as a retrospective study and informed consent was obtained from all patients studied.

\section{Isolation of Genomic DNA}

Genomic DNA was obtained from all patients by using the MagPurix Blood DNA Extraction Kit (Zinexts Life Science Corp., New Taipei City, TAIWAN) according to the manufacturer's specifications.

\section{Targeted Next-generation Sequencing (NGS)}

NEXTflex ${ }^{\oplus}$ TP53 Amplicon Panel (Bioo Scientific Corp., Austin, TX, USA) was used for the enrichment of the coding regions and the intronic regions (up to the area covered by the kit) of TP53 gene. Targeted NGS was performed on Illumina MiSeq NGS System (Illumina Inc., San Diego, CA, USA) using MiSeq Reagent Kit v2 (500-cycles) (Catalog No: MS-102-2003. Illumina Inc., San Diego, CA, USA).

\section{NGS Data Analysis}

Firstly, 'SEQ software' (Genomize, İstanbul, TURKEY) was used for analyzing the raw data according to the reference genome of GRCh37. The minimum coverage-depth was $100 \mathrm{X}$ in all target regions. In addition, Integrative Genomics Viewer (IGV) software was used for evaluating the reads. [6,7]

Secondly, variants were detected based on minimum 5X coverage-depth per allele. Then, they were filtered by the following criteria:

1. Variants that had all submissions as Benign (B)/ Likely Benign (LB) in ClinVar database were excluded, and

2. Variants that had allele frequency $>5 \%$ in any population databases (1000Genomes, ExAC, ESP) were excluded, and

3. Variants that were in the coding and intronic regions were included.

Finally, filtered variants were interpreted based on ACMG Standards and Guidelines recommendations. [8] Ensembl, dbSNP, ClinVar, PubMed, International Agency for Research on Cancer (IARC) TP53 database,[9] LOVD (Leiden Open Variation Database), HGMD $^{\circledR}$ Professional 2017.3 (Human Gene Mutation Database) and ExAC, ESP, 1000Genomes population databases, and in silico prediction tools [10-13] were used for interpreting variants.

\section{Confirmation Analysis}

The pathogenic variants revealed by the NGS analysis were confirmed by performing Sanger sequencing on 


\begin{tabular}{|c|c|c|c|c|}
\hline Patien & Identified variants & Evaluated as & ClinVarID & dbSNP \\
\hline 1 & TP53:NM_000546:c.469G>T(p.Val157Phe)(Exon5) Heterozygous & Likely pathogenic (known) & 12353 & rs121912654 \\
\hline 2 & TP53:NM_000546:c.638G>A(p.Arg213Gln)(Exon6) Heterozygous & Pathogenic (known) & 135359 & rs587778720 \\
\hline 3 & TP53:NM_000546:c.332T>C(p.Leu111Pro)(Exon4) Heterozygous & Likely pathogenic (known) & 376630 & rs1057519997 \\
\hline 4 & TP53:NM_000546:c.817C>T(p.Arg273Cys)(Exon8) Heterozygous & Pathogenic (known) & 43594 & rs121913343 \\
\hline TP & P53:NM_000546:c.1078G>A(p.Gly360Arg)(Exon10) Heterozygous & VUS & 186887 & rs786203298 \\
\hline
\end{tabular}

VUS: Variant of uncertain clinical significance

Table 2 Number of the variants according to age distribution

\begin{tabular}{lcc}
$\begin{array}{l}\text { Age at diagnosis } \\
\text { (between) }\end{array}$ & $\begin{array}{c}\text { Case } \\
\text { number }\end{array}$ & $\begin{array}{c}\text { Variant } \\
\text { identified }\end{array}$ \\
\hline $24-29$ & 5 & $2(\mathrm{LP}, \mathrm{LP})$ \\
$30-39$ & 43 & $2(\mathrm{P}, \mathrm{P})$ \\
$40-48$ & 52 & 1 (VUS) \\
Total & 100 & 5 \\
\hline
\end{tabular}

LP: Likely pathogenic; P: Pathogenic; VUS: Variant of uncertain clinical significance

ABI PRISM 3500 DNA analyzer (Applied Biosystems, Foster City, CA, USA).

Multiplex Ligation-dependent Probe Amplification Analysis (MLPA)

SALSA $^{\oplus}$ MLPA $^{\oplus}$ P056 TP53 probemix (MRC-Holland, Amsterdam, the Netherlands) was used for MLPA analysis in patients who had no pathogenic variants. The Coffalyser software (MRC-Holland, Amsterdam, the Netherlands) was used for interpreting the MLPA data.

\section{Results}

Five variants were detected in five of 100 (5\%) patients (Table 1). Four of five variants were assessed as known as pathogenic/likely pathogenic. These variants were confirmed by Sanger sequencing. One of five variant was identified as VUS. All of five variants were found to be heterozygous. No deletion or duplication was detected in the TP53 gene in patients who had no pathogenic/likely pathogenic variant.

The mean age at diagnosis for all patients was 39.1 years (range 24-48 years) (Table 2). The mean age of four patients who had pathogenic/likely pathogenic variants at diagnosis was 30.2 , with a range of 24-38 years.

\section{Discussion}

$\mathrm{BC}$ is the most common malignancy among women worldwide. Although most cases of $\mathrm{BC}$ are sporadic, approximately $5-10 \%$ of $\mathrm{BC}$ cases have a hereditary $\mathrm{BC}$. The majority of inherited $\mathrm{BC}$ in women arises from mutations in BRCA1 and BRCA2 genes. Other rare causes of hereditary $\mathrm{BC}$ include mutations in the highpenetrance genes, such as TP53, PTEN, CDH1, STK11, PALB2, and mismatch repair (MMR) genes.

LFS, also known as SBLA (Sarcoma, Breast, Leukemia and Adrenal Gland) cancer syndrome, is a cancer predisposition disease with an autosomal dominant inheritance. LFS occurs at an early age. LFS arises from a mutation in the TP53 gene. TP53 gene is activated when DNA is damaged. Cell cycle progression is delayed, and DNA is repaired. If TP53 protein is not activated by mutations, cells with damaged DNA can survive and proliferate to malignant transformation. More than 300 germline variants have been reported in the TP53 gene. [14] The majority of variants are missense variants. Most of them are detected in the DNAbinding region of the gene (exons 4 to 8 ).

The clinical spectrum and age in LFS may vary in populations.[15] Patients with TP53 gene mutation have a high risk of developing a second malignancy. [16] Women with LFS have a high risk of developing $\mathrm{BC}$ with an early age onset. The majority of BC in LFS occurs between 15 and 44 age of years.[17] The lifetime risk of cancer for women is estimated to be about $90 \%$ by 60 years of age.[18] Germline molecular testing (sequencing/MLPA) of TP53 gene is required for definitive diagnosis of LFS. There are several different criteria (such as classical LFS, Li-Fraumeni-like (LFL) syndrome, Chompret criteria) to determine patients for molecular testing in the TP53 gene. However, not all patients with TP53 gene mutation meet these clinical criteria.[15]

We identified two pathogenic and two likely pathogenic variants that were located in the DNA-binding 


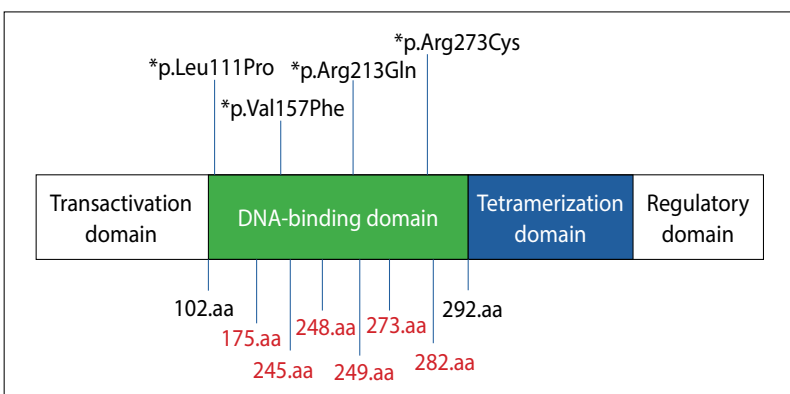

Fig. 1. Illustration of the TP53 gene showing domains of the protein together with the location of the hotspot mutations (shown in red).

${ }^{*}$ Indicates $\mathrm{P} / \mathrm{LP}$ variants identified in this study; aa: Amino acid; P: Pathogenic; LP: Likely pathogenic.

domain in this study (Fig. 1). All of them had been reported in IARC TP53 [9] and ClinVar databases. One of the pathogenic variants was found as c.638G $>A$ (p.Arg213Gln) (Exon6) in patient 2 (Fig. 2). She was 38 years old and diagnosed at 38 years old. Her mother died at 60 years old because of spinal cord cancer. Her uncle (maternal) had prostate cancer and died at 65 years old. Her daughter was healthy (18 years old). The pathogenic variant was also found in her daughter. The second pathogenic variant was detected in patient 4. It was one of the hotspot mutations as c. $817 \mathrm{C}>\mathrm{T}$ (p. Arg273Cys) (Exon8) (Fig. 3). She was 42 years old. The first primary tumor was detected on the right breast at 32 years old, and the second primary tumor was oc- curred on the left breast at 42 years old. Her father diagnosed with gastric cancer at 64 years old and died 65 years old. One of the likely pathogenic variants was revealed in patient 1 as c.469G $>\mathrm{T}$ (p.Val157Phe) (Exon5) (Fig. 4). She was 24 years old and diagnosed at 24 years old. Her father died because of a brain tumor. She had three healthy sisters. Her uncle's (paternal) daughter had a BC. The second likely pathogenic variant was found in patient 3 as c.332T $>C$ (p.Leu111Pro) (Exon4) (Fig. 5). She was 37 years old. She diagnosed with BC at 27 years old. Her father had a brain tumor and died at 40 years old. Her grandmother (paternal) died at 40 years old because of BC. We also identified a variant [c.1078G $>$ A(p.Gly360Arg) (Exon10)] as VUS in patient 5, which was reported in ClinVar and IARC databases. She was 41 years old and diagnosed at 40 years old. She had not a family history.

There are several studies that reported the frequency of TP53 mutations in patients with BRCA negative early-onset BC. These studies were conducted in different ethnic groups with different age thresholds (Table 3). For example, Lalloo et al.[19] carried out a mutation analysis of the TP53 gene by Sanger sequencing in 82 English BC patients diagnosed at $\leq 30$ age of years. They identified four variants $(4.9 \% ; 4 / 82)$. In another study, Bougeard et al.[20] revealed four variants in 45 French BC patients $(0.7 \% ; 4 / 45)$ diagnosed at $<33$ years. The other study was performed by Ginsburg et al.[4] in $95 \mathrm{BC}$ patients diagnosed at $<30$ age of years from different ethnicities. They did not find any muta-

Table 3 Summary of the studies of mutation analysis of the TP53 gene in patients with BRCA negative early-onset BC

\begin{tabular}{|c|c|c|c|c|c|c|}
\hline Year & Study [ref] & $\begin{array}{c}\text { Age at } \\
\text { diagnosis }\end{array}$ & $\begin{array}{c}\text { Case } \\
\text { number }\end{array}$ & $\begin{array}{c}\text { Variant } \\
\text { identified }\end{array}$ & Methods & Ethnicity \\
\hline 2006 & Lalloo et al. [19] & $\leq 30$ & 82 & $4(4.9 \%)$ & Sanger sequencing & English \\
\hline 2008 & Bougeard et al. [20] & $<33$ & 45 & $3(0.7 \%)$ & Sanger sequencing & French \\
\hline 2009 & Ginsburg et al. [4] & $<30$ & 95 & 0 & Sanger sequencing & Multi-ethnic \\
\hline \multirow[t]{2}{*}{2009} & Gonzalez et al. [21] & $<30$ & 14 & $1(7 \%)$ & Sanger sequencing & American \\
\hline & & $30-49$ & 15 & 0 & & \\
\hline 2010 & Mouchawar et al. [17] & $<30$ & 41 & $2(4.9 \%)$ & Sanger sequencing and MLPA & Australian \\
\hline 2012 & Lee et al. [5] & $\leq 35$ & 83 & $5(6 \%)$ & Sanger sequencing & Asian (multi-ethnic) \\
\hline 2012 & Rashid et al. [22] & $\leq 40$ & 105 & $1(1.5 \%)$ & DHPLC and Sanger sequencing & Pakistani \\
\hline 2013 & Carraro et al. [23] & $\leq 35$ & 43 & $1(2.3 \%)$ & Sanger sequencing & Brazilian \\
\hline 2015 & Yang et al. [1] & $\leq 30$ & 20 & $2(10 \%)$ & NGS & Chinese \\
\hline \multirow[t]{2}{*}{2019} & Gallardo-Alvarado et al. [24] & $\leq 36$ & 53 & $5(9.4 \%)$ & NGS & Mexican \\
\hline & & $37-45$ & 25 & 0 & & \\
\hline \multirow[t]{3}{*}{ In this study } & Özdemir et al. & $24-29$ & 5 & $2(40 \%)$ & NGS and MLPA & Turkish \\
\hline & & $30-39$ & 43 & $2(4.6 \%)$ & & \\
\hline & & $40-48$ & 52 & 0 & & \\
\hline
\end{tabular}

MLPA: Multiplex ligation-dependent probe amplification; DHPLC: Denaturing high-performance liquid chromatography; NGS: Next-generation sequencing 


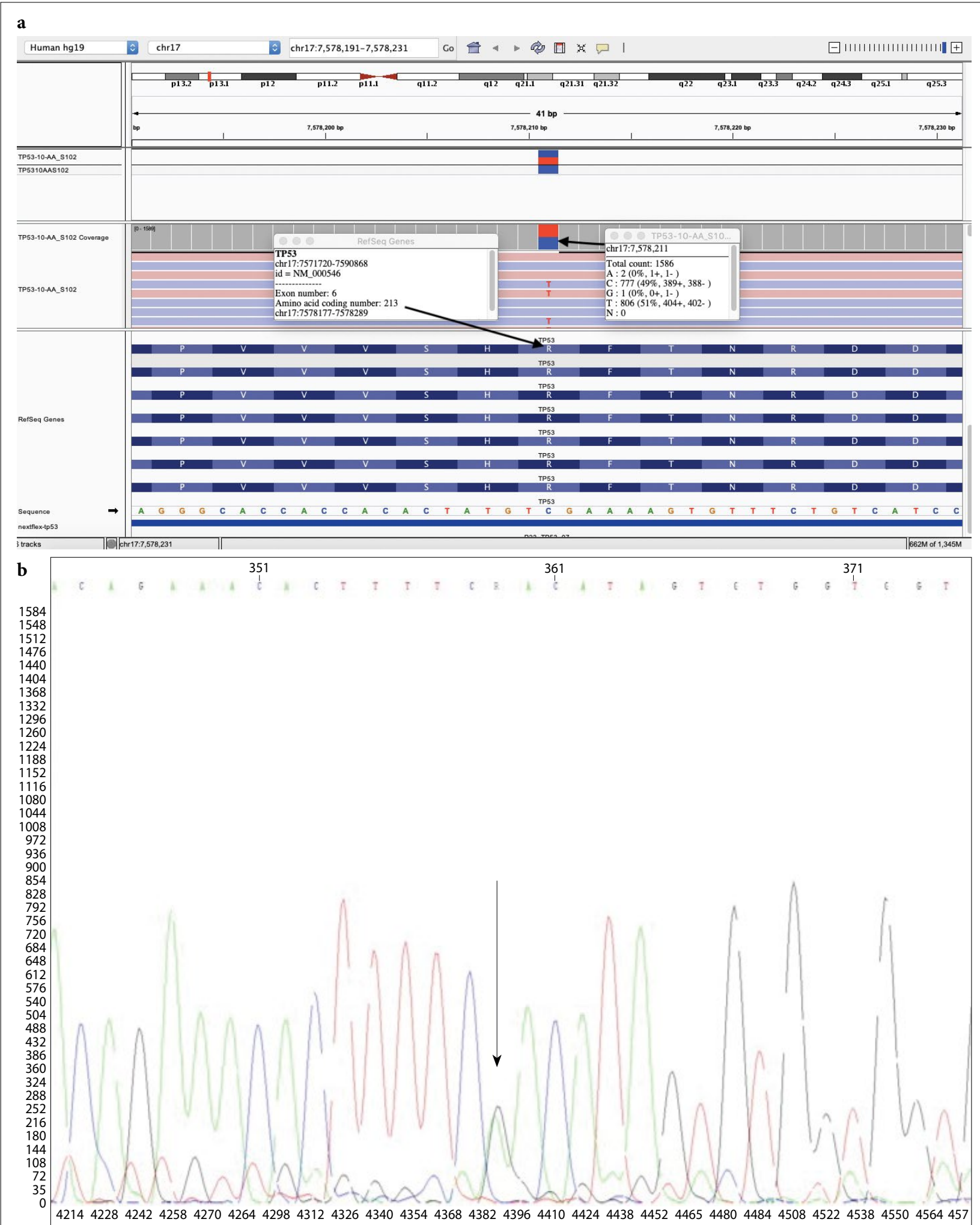

Fig. 2. IGV image (a) and electropherogram (b) of patient-2 with a pathogenic variant [TP53:NM_000546:c.638G>A(p. R213Q)(Exon6) Heterozygous]. The black arrows indicate a variant.

IGV: Integrative genomics viewer. 
a
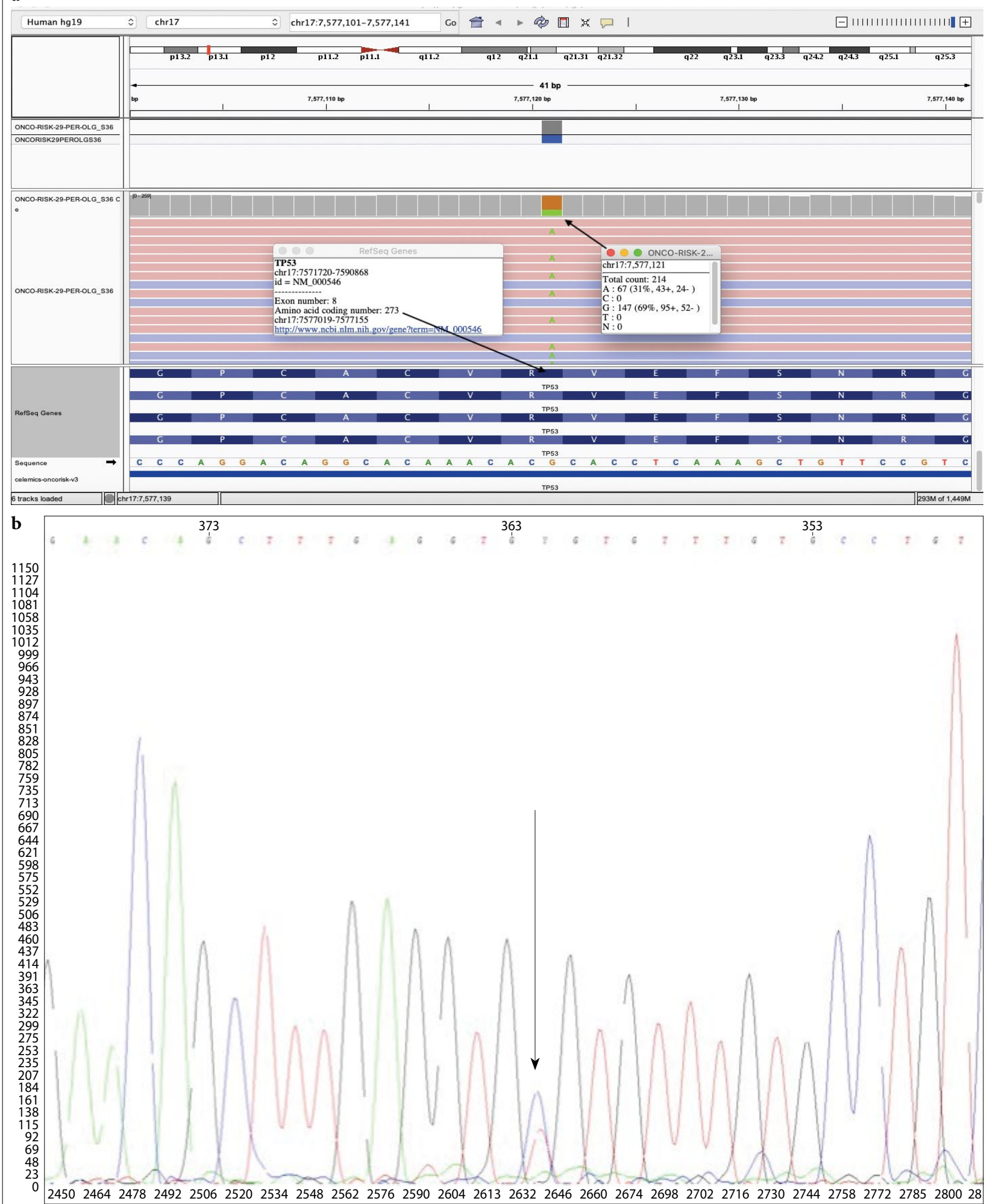

Fig. 3. IGV image (a) and electropherogram (b) of patient-4 with a pathogenic variant [TP53:NM_000546:c.817C>T(p. Arg273Cys)(Exon8) Heterozygous]. The black arrows indicate a variant. IGV: Integrative genomics viewer. 
a
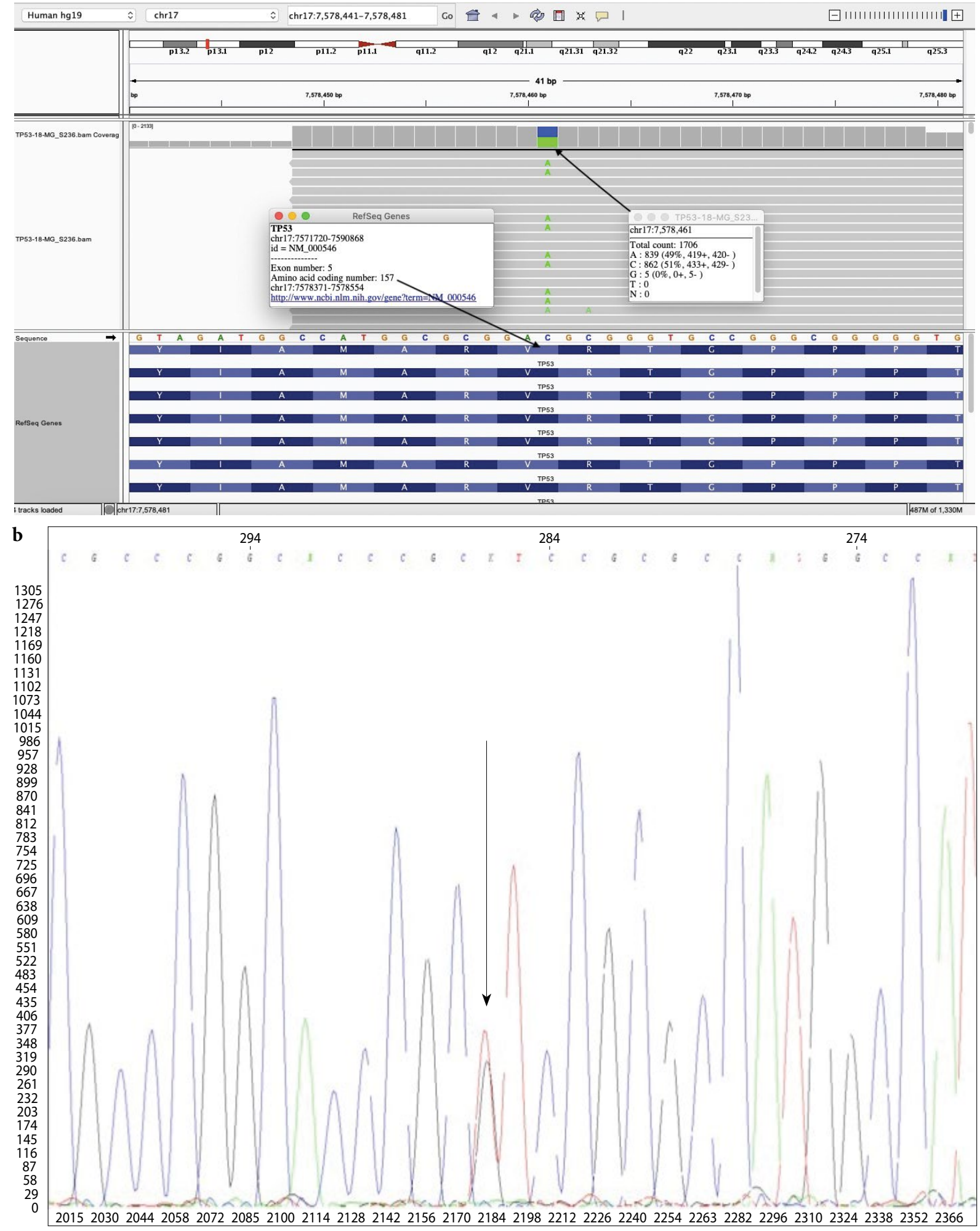

Fig. 4. IGVimage(a)andelectropherogram(b)ofpatient-1 withalikelypathogenicvariant[TP53:NM_000546:c.469G>T(p. Val157Phe)(Exon5) Heterozygous]. The black arrows indicate a variant.

IGV: Integrative genomics viewer. 


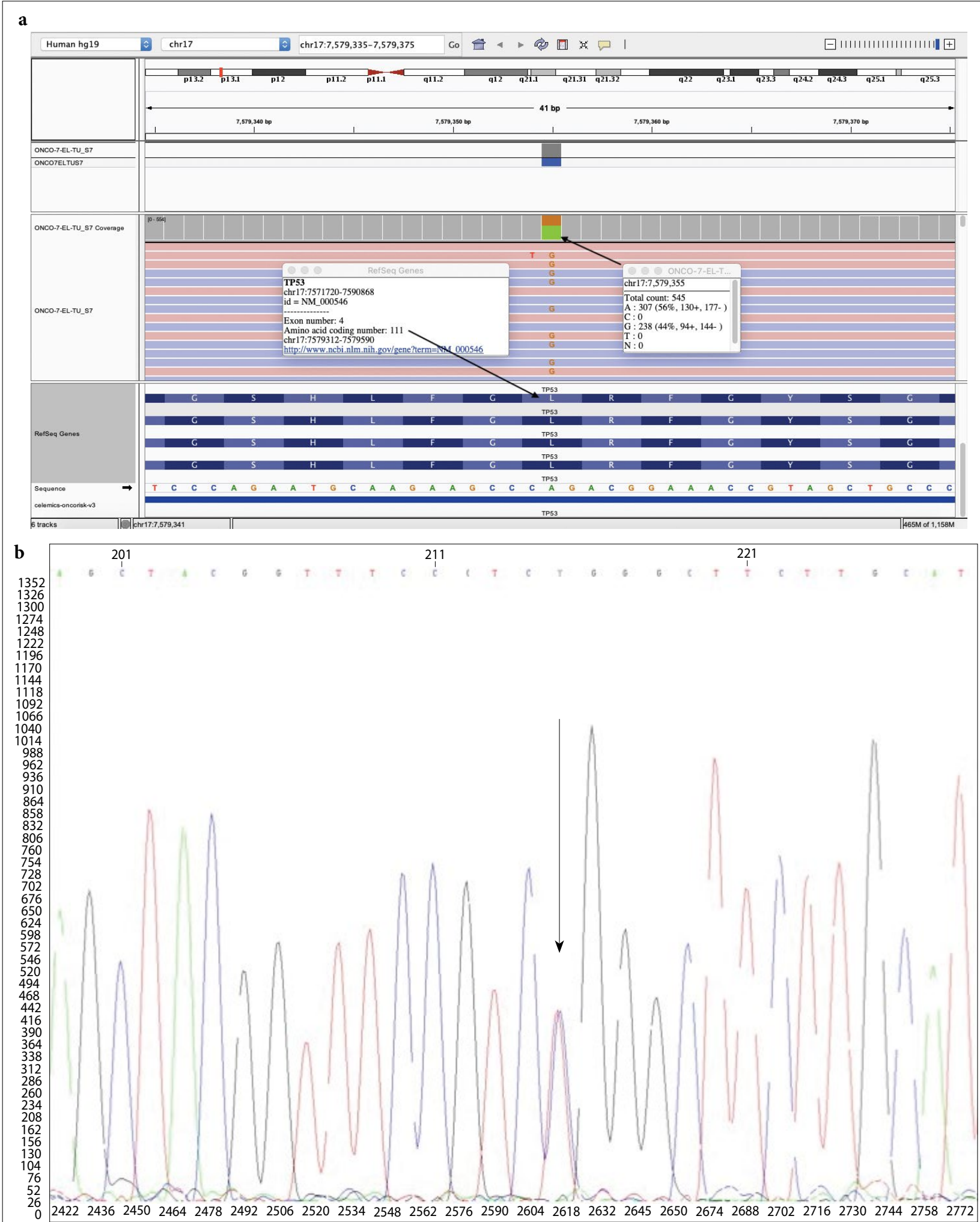

Fig. 5. IGV image (a) and electropherogram (b) of patient-3 with a likely pathogenic variant [TP53:NM_000546:c.332T>C(p.Leu111Pro) (Exon4) Heterozygous]. The black arrows indicate a variant. IGV: Integrative genomics viewer. 
tion in the TP53 gene. Gonzalez et al.[21] revealed one variant in 14 American patients $(7 \% ; 1 / 14)$ with BC diagnosed at $<30$ years. All of the patients had no family history. In the same study, no mutation was found in $15 \mathrm{BC}$ patients diagnosed between ages 30 and 49. However, in our study, we detected two variants in five $B C$ patients diagnosed at $<30$ years and two variants in 95 BC patients diagnosed between $30-48$ years (Table 2). In another study, Mouchawar et al.[17] performed mutation analyses by Sanger sequencing and by MLPA method in 41 Australian patients with $\mathrm{BC}$ regardless of family history and diagnosed at $<30$ years. Two variants were identified $(4.9 \% ; 2 / 41)$. One of them was [(p. Arg 175His) (Exon6)] found in a patient who diagnosed at 24 years old. The other variant was found as a large deletion encompassing exon 2-4. She was diagnosed at 26 years old. Lee et al.[5] identified five variants in multi-ethnic 83 Asian patients $(6 \%$; 5/83) with BC diagnosed at $\leq 35$ years of age. The median age of onset of $\mathrm{BC}$ was 31 years. In the other study, Rashid et al.[22] detected the frequency of TP53 mutations in 105 Pakistani patients with BC. Of 67 patients diagnosed at $\leq 30$ years of age had no family history. The remaining 38 patients diagnosed at $\leq 40$ years of age had a family history. Only one variant was revealed in this study (1\%; 1/105). It was a frameshift mutation (c.499_500delCA) in exon 5. It was found in a 28 -year-old patient with no family history. Carraro et al.[23] identified only one variant in 43 Brazilian patients $(2.3 \%$; $1 / 43)$ with $\mathrm{BC}$ diagnosed $\leq 35$ years of age. It was found as c. $427 \mathrm{G}>\mathrm{A}$ (p.Val143Met) in a 24 years old patient who had no family history. Yang et al.[1] performed a mutation analysis of 152 genes associated with hereditary cancers using NGS in 99 Chinese patients with BC. They identified three variants in the TP53 gene (3\%; 3/99). Of two variants were found in patients with $\mathrm{BC}$ diagnosed $\leq 30$ years of age. They accounted for $10 \%(2 / 20)$ of all patients with $\mathrm{BC}$ diagnosed at $\leq 30$ years in their study. In another study was performed in the Mexican population by Gallardo-Alvarado et al.[24] They tested 78 Mexican patients with $\mathrm{BC}$ diagnosed at $<45$ years of age. They determined the frequency of TP53 germline mutation using NGS as $6.4 \%$ (5/78). All five patients with $\mathrm{BC}$ diagnosed before the age of $36(9.4 \% ; 5 / 53)$.

BC patients with TP53 mutation and their relatives who have the same mutation can benefit from surveillance programs for various cancers to aim at early tumor detection.[25] The surveillance program for BC includes breast self-examination, clinical examination and imaging. In general, monthly breast self-examination starting from the age of 18 years is recommended. Clinical breast examination is recommended every 6-12 months, starting from the age of 20-25 years. Breast MRI annually is recommended at 20-75 years. Mammography is controversial because there are several reports suggesting that cancers induced by radiation are more common in patients with LFS.[26,27] While some of the guidelines suggest annual breast MRI and mammography, some guidelines recommend annual breast MRI screening without mammography.[2] Therefore, patients should be informed about the risks of malignancy associated with radiotherapy. Risk-reducing mastectomy should be evaluated in BC patients with TP53 mutation because of the high contralateral BC risk. Moreover, the option for risk-reducing bilateral mastectomy should be considered in women without cancer with TP53 mutation.[2] Recommendations for other cancer risks include comprehensive physical examinations every 6-12 months, colonoscopy and upper endoscopy starting at 25 age of years every 2-5 years, [2] dermatological examination especially for melanoma annually starting at 18 years of age.[25] Whole-body MRI, especially for sarcomas, is recommended once a year.[25,28]

Brain MRI is recommended once a year for brain tumors (can be performed as part of whole-body MRI or as a separate examination).[25]

\section{Conclusion}

In conclusion, TP53 gene mutation analyses should be performed in BRCA-negative BC patients under 50 years of age although differences in the threshold for age because there is an increased lifetime risk for various cancers in LFS. TP53 gene mutation analysis can be performed as a single test or as a part of a multigene panel using NGS because NGS technology provides simultaneous analysis of multiple genes in a single test at a comparable cost to Sanger sequencing.

Peer-review: Externally peer-reviewed.

Conflict of Interest: The authors have no conflicts of interest to declare.

Ethics Committee Approval: Ethics committee approval was received for this study as a retrospective study.

Financial Support: The authors declared that this study has received no financial support.

Authorship contributions: Concept - T.R.Ö., Ö.Ö.K., M.E., M.D., G.D.; Design - T.R.Ö., Ö.Ö.K., K.M.E., M.S.G., M.E.; Supervision - T.R.Ö., Ö.Ö.K., M.E., M.D., G.D., K.M.E., M.S.G., B.Ö., Ö.K., A.K.; Funding - None; Materials - T.R.Ö., M.E., M.D., G.D.; Data collection and/or process- 
ing - T.R.Ö., Ö.Ö.K., M.E., M.D., G.D., K.M.E., M.S.G., B.Ö., Ö.K., A.K.; Data analysis and/or interpretation - T.R.Ö., Ö.Ö.K., K.M.E., M.S.G., B.Ö., Ö.K., A.K.; Literature search T.R.Ö., Ö.Ö.K., M.E., M.D., G.D., K.M.E., M.S.G., B.Ö., Ö.K., A.K.; Writing - T.R.Ö., Ö.Ö.K., M.E., M.D., G.D., K.M.E., M.S.G., B.Ö., Ö.K., A.K.; Critical review - T.R.Ö., Ö.Ö.K., M.E., M.D., G.D., K.M.E., M.S.G., B.Ö., Ö.K., A.K.

\section{References}

1. Yang X, Wu J, Lu J, Liu G, Di G, Chen C, et al. Identification of a comprehensive spectrum of genetic factors for hereditary breast cancer in a Chinese population by next-generation sequencing. PLoS One 2015;10(4):e0125571.

2. Schon K, Tischkowitz M. Clinical implications of germline mutations in breast cancer: TP53. Breast Cancer Res Treat 2018;167(2):417-23.

3. Salmon A, Amikam D, Sodha N, Davidson S, BaselVanagaite L, Eeles RA, et al. Rapid development of post-radiotherapy sarcoma and breast cancer in a patient with a novel germline 'de-novo' TP53 mutation. Clin Oncol (R Coll Radiol) 2007;19(7):490-3.

4. Ginsburg OM, Akbari MR, Aziz Z, Young R, Lynch H, Ghadirian P, et al. The prevalence of germ-line TP53 mutations in women diagnosed with breast cancer before age 30. Fam Cancer 2009;8(4):563-7.

5. Lee DS, Yoon SY, Looi LM, Kang P, Kang IN, Sivanandan K, et al. Comparable frequency of BRCA1, BRCA2 and TP53 germline mutations in a multi-ethnic Asian cohort suggests TP53 screening should be offered together with BRCA1/2 screening to early-onset breast cancer patients. Breast Cancer Re. 2012;14(2):R66.

6. Robinson JT, Thorvaldsdóttir H, Winckler W, Guttman M, Lander ES, Getz G, et al. Integrative genomics viewer. Nat Biotechnol 2011;29(1):24-6.

7. Thorvaldsdóttir H, Robinson JT, Mesirov JP. Integrative Genomics Viewer (IGV): high-performance genomics data visualization and exploration. Brief Bioinform 2013;14(2):178-92.

8. Richards S, Aziz N, Bale S, Bick D, Das S, Gastier-Foster $\mathrm{J}$, et al. Standards and guidelines for the interpretation of sequence variants: a joint consensus recommendation of the American College of Medical Genetics and Genomics and the Association for Molecular Pathology. Genet Med 2015;17(5):405-24.

9. Bouaoun L, Sonkin D, Ardin M, Hollstein M, Byrnes G, Zavadil J, et al. TP53 Variations in Human Cancers: New Lessons from the IARC TP53 Database and Genomics Data. Hum Mutat 2016;37(9):865-76.

10. Schwarz JM, Cooper DN, Schuelke M, Seelow D. MutationTaster2: mutation prediction for the deep-sequencing age. Nat Methods 2014;11(4):361-2.
11. Adzhubei IA, Schmidt S, Peshkin L, Ramensky VE, Gerasimova A, Bork P, et al. A method and server for predicting damaging missense mutations. Nat Methods 2010;7(4):248-9.

12. Kumar P, Henikoff S, Ng PC. Predicting the effects of coding non-synonymous variants on protein function using the SIFT algorithm. Nat Protoc 2009;4(7):107381.

13. Desmet FO, Hamroun D, Lalande M, Collod-Béroud G, Claustres M, Béroud C. Human Splicing Finder: an online bioinformatics tool to predict splicing signals. Nucleic Acids Res 2009;37(9):e67.

14. Lindor NM, McMaster ML, Lindor CJ, Greene MH; National Cancer Institute, Division of Cancer Prevention, Community Oncology and Prevention Trials Research Group. Concise handbook of familial cancer susceptibility syndromes - second edition. J Natl Cancer Inst Monogr 2008;(38):1-93.

15. Rana HQ, Gelman R, LaDuca H, McFarland R, Dalton E, Thompson J, et al. Differences in TP53 Mutation Carrier Phenotypes Emerge From Panel-Based Testing. J Natl Cancer Inst 2018;110(8):863-70.

16. Bougeard G, Renaux-Petel M, Flaman JM, Charbonnier C, Fermey P, Belotti M, et al. Revisiting Li-Fraumeni Syndrome From TP53 Mutation Carriers. J Clin Oncol 2015;33(21):2345-52.

17. Mouchawar J, Korch C, Byers T, Pitts TM, Li E, McCredie MR, et al. Population-based estimate of the contribution of TP53 mutations to subgroups of earlyonset breast cancer: Australian Breast Cancer Family Study. Cancer Res 2010;70(12):4795-800.

18. Mai PL, Best AF, Peters JA, DeCastro RM, Khincha PP, Loud JT, et al. Risks of first and subsequent cancers among TP53 mutation carriers in the National Cancer Institute Li-Fraumeni syndrome cohort. Cancer 2016;122(23):3673-81.

19. Lalloo F, Varley J, Moran A, Ellis D, O'dair L, Pharoah $\mathrm{P}$, et al. BRCA1, BRCA2 and TP53 mutations in very early-onset breast cancer with associated risks to relatives. Eur J Cancer 2006;42(8):1143-50.

20. Bougeard G, Sesboüé R, Baert-Desurmont S, Vasseur $\mathrm{S}$, Martin C, Tinat J, et al. Molecular basis of the LiFraumeni syndrome: an update from the French LFS families. J Med Genet 2008;45(8):535-8.

21. Gonzalez KD, Noltner KA, Buzin CH, Gu D, WenFong CY, Nguyen VQ, et al. Beyond Li Fraumeni Syndrome: clinical characteristics of families with p53 germline mutations. J Clin Oncol 2009;27(8):1250-6.

22. Rashid MU, Gull S, Asghar K, Muhammad N, Amin A, Hamann U. Prevalence of TP53 germ line mutations in young Pakistani breast cancer patients. Fam Cancer 2012;11(2):307-11.

23. Carraro DM, Koike Folgueira MA, Garcia Lisboa BC, Ribeiro Olivieri EH, Vitorino Krepischi AC, de Car- 
valho $\mathrm{AF}$, et al. Comprehensive analysis of BRCA1, BRCA2 and TP53 germline mutation and tumor characterization: a portrait of early-onset breast cancer in Brazil. PLoS One 2013;8(3):e57581.

24. Gallardo-Alvarado LN, Tusié-Luna MT, Tussié-Luna MI, Díaz-Chávez J, Segura YX, Bargallo-Rocha E, et al. Prevalence of germline mutations in the TP53 gene in patients with early-onset breast cancer in the Mexican population. BMC Cancer 2019;19(1):118.

25. Kratz CP, Achatz MI, Brugières L, Frebourg T, Garber JE, Greer MC, et al. Cancer Screening Recommendations for Individuals with Li-Fraumeni Syndrome. Clin Cancer Res 2017;23(11):e38-e45.
26. Limacher JM, Frebourg T, Natarajan-Ame S, Bergerat JP. Two metachronous tumors in the radiotherapy fields of a patient with Li-Fraumeni syndrome. Int $\mathrm{J}$ Cancer 2001;96(4):238-42.

27. Heymann S, Delaloge S, Rahal A, Caron O, Frebourg T, Barreau L, et al. Radio-induced malignancies after breast cancer postoperative radiotherapy in patients with Li-Fraumeni syndrome. Radiat Oncol 2010;5:104.

28. Ballinger ML, Best A, Mai PL, Khincha PP, Loud JT, Peters JA, et al. Baseline Surveillance in Li-Fraumeni Syndrome Using Whole-Body Magnetic Resonance Imaging: A Meta-analysis. JAMA Oncol 2017;3(12):1634-9. 